\title{
ESTUDIOS
}

\section{El Cuadro de Costumbres, el Cuento y la Posibilidad de un Deslinde}

Como si se tratara de un hecho indiscutible, la historia literaria suele repetir que el cuadro de costumbres es la forma narrativa que prefigura o engendra al cuento literario. ${ }^{1}$ Es obvio que esa generalización tiene su razón de ser; pero sería un error tomarla al pie de la letra sobre todo porque se alude en esas observaciones a dos formas de la narración breve que, a mi entender, difieren notablemente en su organización interna.

A manera de observación inicial, estimo que se produce un equivoco innecesario cuando inferimos que existe, en términos formales, una causalidad directa entre el artículo de costumbres y el cuento literario. ${ }^{2}$ Pero lo cierto es que tanto en las letras españolas como en las hispanoamericanas sólo ocasionalmente se han practicado los deslindes que nos servirian para fijar con exactitud la evolución histórica y formal de la narrativa breve. 3 Me refiero, por ejemplo, a que no contamos aún con una delimitación precisa entre el cuadro de costumbres y el cuento literario, a pesar de que la bibliografía sobre ambas formas es ya muy extensa. ${ }^{4}$ En las páginas que siguen quiero proponer algunas distinciones formales que, hasta hoy, aún no se han formulado con precisión necesaria.

Al retroceder en la historia literaria, me parece curioso que Menéndez y Pelayo seleccionara al Rinconete y Cortadillo de Cervantes como modelo preeminente del relato costumbrista. Según el erudito español, desde entonces el cuadro de costumbres "existe con jurisdicción independiente de la novela y en formas variadísimas." Y asî prosigue para definirlo como "narración que se cifra en la acabada y realista pintura de los héroes." 5 A esos comentarios ocasionales de Menéndez y Pelayo podrǐan añadirse innumerables matizaciones que 
sobre el mismo tema ofrecían en América el colombiano José Caicedo Rojas (1816-1898), el cubano Cirilo de Villaverde (1812-1894) y el argentino Juan Bautista Alberdi (1810-1884), entre otros. 6 Para destacar principalmente la función utilitaria e historicista del cuadro de costumbres, Caicedo Rojas insistía en que:

Los artǐculos de costumbres, como complemento indispensable de la Historia, son de grande importancia para dar a conocer en todos sus pormenores una sociedad, un pueblo en su modo íntimo de ser. La Historia se limita a narrar los grandes hechos, las peripecias, los triunfos, las vicisitudes, las guerras, las hazañas, las diferentes situaciones por las cuales ha pasado una nación en el largo periodo de su infancia y desarrollo. ${ }^{7}$

En España, sin mayor éxito, se especuló abundantemente en torno a la configuración y funciones del artǐculo de costumbres. Ramón Mesoneros Romanos - que tanto admiraron los costumbristas americanos- afirmaba que su Panorama matritense fue concebido para suplir la falta de novelas modernas y para recrear, a la vez, "las narraciones fantásticas, los sueños y las alegorías a la manera de Quevedo, Espinel, Mateo Alemán y Diego de Torres."8 Pero ocurre que el concepto de modernidad a que alude Mesoneros radica en textos clásicos que a duras penas podían aprovecharse como esquemas apropiados para la creación de una novelística renovadora. De entrada, esa diversidad de metas contradictorias anticipa con suficiente claridad algunos de los equívocos inherentes al cuadro de costumbres como género literario. Visto en ese contexto, no resulta convincente el esfuerzo renovador que persegulan Mesoneros y sus contemporáneos. Por otra parte, la postura que asumía el relator denota un nivel de afectación que le lleva a elaboraciones ingenuas de la materia narrativa. El escritor costumbrista persistia, por ejemplo, en la añoranza de giros anticuados y en la glorificación nostálgica de hábitos y valores que aún estaban vigentes en la sociedad española de aquella época. ${ }^{9}$ La exaltación simplista de lo añejo fue por muchos años pose predilecta del narrador costumbrista que insistǐa -como lo apuntó Montesinos- en echarse encima los años que no tenỉa para fortalecer de alguna manera el registro informativo del texto. $10 \mathrm{~A}$ esa actitud ligera, $\mathrm{y}$ a veces histriónica, pueden atribuirse muchas de las inconsistencias que padece el flujo de la escritura. Como consecuencia de ello resaltan habitualmente las rupturas del hilo narrati- 
vo y el contrapunteo sobresaltado de anécdotas inconclusas y matizaciones conceptuales.

La confusión que envuelve al relato de costumbres en nuestra historia literaria se debe también a que esas narraciones surgieron en un vacío teórico y sin el apoyo formal de modelos prestigiosos. Son, además, narraciones que con frecuencia aspiran simultáneamente al prestigio de la investigación histórica y a la expresividad inherente a la creación literaria. Esa postura ambivalente sobresale de igual manera en los pronunciamientos que el argentino Esteban Echeverrǐa (1805-1851), entre muchos, resumió con el énfasis que le caracteriza. Según él lo vió, las funciones primordiales de la narración costumbrista serían "Mostrar en seguida la práctica de las naciones cultas cuyo estado social sea análogo al nuestro y confrontar siempre los hechos con la teoría o la doctrina de los publicistas más adelantados." 11 De esa manera, el texto fue visto como materia idónea para la divulgación cultural y, a la vez, como instrumento proselitista. Esa variedad de metas y responsabilidades nos permite explicar la ambigüedad formal y de propósitos que determina la hechura del relato costumbrista. Es, en parte, por esas arbitrariedades que me parece erróneo vincular - como tantas veces se ha hecho- la estampa costumbrista a las Novelas ejemplares; principalmente porque los textos de Cervantes son creaciones imaginativas que alcanzan una organización muy refinada del discurso narrativo. ${ }^{12}$ Además, al ubicar los textos en el proceso histórico, creo necesario insistir en que las Novelas ejemplares consolidaron un ciclo evolutivo de la narración breve que tomará rumbos no siempre afines a los objetivos del costumbrismo; 13 ciclo que adquiere continuidad en las narraciones de Alonso Castillo Solórzano (1584-1648), Jerónimo Salas Barbadillo (1552-1635) y en los complejos "saraos" y "maravillas" de María de Zayas (1590-1661). En el siglo XIX la expansión de ese proceso evolutivo mantuvo un nivel de continuidad que se verifica, por ejemplo, en "La tormenta" de Rosalía de Castro (1837-1885) y en "La voz del silencio" entre otras leyendas de Bécquer.

Pero si en definitiva existe un punto de enlace entre esa corriente de invención narrativa que inaugura Cervantes y el relato de costumbres, el vínculo habrïa que buscarlo en los hallazgos de la novela picaresca; hallazgos que, si bien se ve, los costumbristas aprovecharon con lamentable superficialidad. Y quizá no pudo ser de otra manera. Sin insistir demasiado en ello, repárese que la narración costumbrista, en contraste con la picaresca, no intentó una exploración de la vida 
anterior ni se detuvo ante la enajenación y las miserias que asediaron a la sociedad decimonónica. ${ }^{14}$ Sobre todo en España, el artǐculo de costumbres se ofrece como una literatura que apenas cuestiona el contexto social de que procede y menos aún el lenguaje de que se vale. El costumbrismo produjo un vasto corpus de textos que sólo ocasionalmente rebasan el perïmetro estrecho de esa burguesǐa provinciana que fue su fin y punto de partida. En ese ámbito tan reducido, los textos de Mariano J. de Larra serán, en más de un sentido, la excepción. En "Casarse pronto y mal" y en "Modos de vivir que no dan de vivir," Larra problematiza vivencias y actitudes que poco o nada tienen que ver con la materia pintoresca y festiva que deleitó al costumbrismo. Pero de todas maneras la indagación punzante y la valoración del contexto socio-político serán por necesidad más recias en la prosa costumbrista de América que en España. El estado de crisis y transformación social que trajo la independencia, impuso exigencias de otra indole a las letras americanas. Pero en todo caso, no me parece exacto definir la narración costumbrista como resultado exclusivo de la sociedad y las letras decimonónicas. Estimo que el artículo de costumbres tiene en la tradición hispánica tipologías precursoras que se remontan a la cuentīstica española de raïz popular que alcanzó su mayor difusión a lo largo del siglo XVI y mucho después. ${ }^{15} \mathrm{Me}$ refiero concretamente a relatos tales como "Viaje entretenido" de Agustín de Rojas (1572-1619), El crotalón de Cristóbal de Villalón (1505-1581) u otros muchos que aparecen en la Floresta española (1524) de Melchor de Santa Cruz (1529-1588) y en La Miscelánea de Luis de Zapata Chávez (1526-1595). En las Historias peregrinas (1623) de Gonzalo de Céspedes y Meneses (1585-1638) se bosquejaban ya regiones y tipos de España con una minuciosidad que anticipa los hábitos descriptivos de la narración costumbrista. $16 \mathrm{El}$ autobiografismo que predomina en esos cuentecillos de ocasión -comentados lúcidamente por Marcel Bataillon y Fernando Lázaro Carreter ${ }^{17}$ - y el ansia de verosimilitud, son rasgos que reaparecen muchos años después en la narración breve a lo largo del XIX. ${ }^{18}$ La materia tan desigual que ofrecen esas narraciones populares - según lo. ha demostrado Maxime Chevalier ${ }^{19}$ - penetró en todos los ámbitos de las letras españolas. Es evidente que esos cuentecillos fecundaron tanto a la historiografỉa de Indias como al teatro de Lope de Vega y Ramón de la Cruz. ${ }^{20}$ Por esas narraciones, a veces muy escuetas, desfilan personajes históricos, ficticios y populares, cuyos hábitos suelen tomarse como sinónimo de agudeza o como mero pretexto para la burla caprichosa. Tal es el caso, por 
ejemplo, de La miscelánea de Zapata a que he aludido. Son, además, narraciones que a menudo documentan el contexto social y que de ordinario asumen un sesgo testimonial que las caracteriza. $Y$ esos serán precisamente algunos de los rasgos que con mayor amplitud y sutileza se retoman dos siglos después como distintivos del relato costumbrista. Desde esa perspectiva histórica es oportuno recordar también que el romanticismo - al empeñarse en una vasta reconstrucción imaginativa del pasado- exaltó con entusiasmo el valor de la leyenda y el cuento popular como fuentes documentales.

Al bosquejar someramente algunos antecedentes de la narración costumbrista, no pretendo caracterizarla sin más como una forma autóctona de las letras españolas e hispanoamericanas. De sobra sabemos hoy que El espectador de Addison y L'hermite de la chauseé d'Antin de Victor Etienne Jouy figuran como modelos prominentes para Serafín Estébanez Calderón, Mesoneros y Larra. 21 En ese vasto proceso de relaciones literarias, el cuadro de costumbres alcanzó su configuración definitiva como un resumen -a veces precario- de modelos europeos y fuentes populares de la tradición hispánica. En mi opinión, esa sìntesis de elementos tan diversos, encontró su plenitud formal en las Escenas andaluzas (1847) de Estébanez, en el Panorama de Mesoneros y en varios artículos de Larra tales como "La diligencia" en que predomina abiertamente la materia de ficción.

Según se produce en esos textos, el relato costumbrista será casi siempre una narración de tono confesional que se atiene a un marco temporal fijo y que toma como punto de referencia el contexto social inmediato. Refiriéndose detalladamente a las características generales del relato costumbrista, Montesinos señalaba con razón que "se nota en ellos defectos casi siempre imputables al costumbrismo: un cierto desenfoque, una flojedad de contornos debida a que el interés de la peripecia se sacrifica a los accesorios, a que el autor se complace más en mostrar el modo de estar que el modo de ser de sus personajes." 22

Concebida de esa manera, la narración costumbrista aparece habitualmente como materia edificante que intensifica su expresividad con los recursos de la palabra hablada y que busca, a su vez, el prestigio intelectual que se otorga a la investigación historicista. Por ser así, el artïculo de costumbres adopta, con frecuencia, un cariz paródico y retratista. Sólo que esos relatos tienden a una suerte de retratismo doble que fija tanto la imagen del sujeto en cuestión como la del relator; tendencia esa que revela una bifurcación interna característica del cuadro de costumbres y que es motivada por la postura 
ambivalente que el narrador asume ante el texto. A nivel estructural, ese desdoblamiento reiterado del punto de vista conduce a una yuxtaposición de estratos narrativos desiguales que al ser percibidos de golpe suelen desfigurar la imagen del texto. La narración integra, pues, un discurso mix to que impone al relato una polisemia sintomática del género, pero que en definitiva trastorna la efectividad del mensaje verbal. Esa articulación contradictoria de la materia narrativa era inevitable, si se toma en cuenta que el cuadro de costumbres aparece condicionado, desde un principio, por exigencias ajenas a la organización del discurso narrativo como tal.

La imagen de collage que asociamos con la narración costumbrista, puede verificarse fácilmente con "La feria de Jocotenango" del guatemalteco José Milla (1822-1882) y también en "El diecinueve de marzo" de Mesoneros que aparece en sus Memorias de un setentón (1882). El relato de Milla se comporta como una crónica local que aprovecha los recursos del reportaje; se intercalan anuncios y textos de avisos: "Una buena gratificación por el allasgo [sic] de un gabán ..."23 y a su vez la narración ofrece un suceso imaginario que gradualmente se extravía hacia las áreas laterales del relato y que deriva en una sucesión deshilachada de comentarios accidentales. 24

Al precisar aún más la configuración interna del cuadro de costumbres, veremos que el texto se define como una forma narrativa que tiene su núcleo de tensión en las agudezas o perspicacias que el narrador consigue. Para lograrlo, el relato se circunscribe a priori a un registro de vivencias que el relator necesariamente comparte con su público inmediato. De hecho, la escritura se afirma en su capacidad para reproducir un ambiente que el público vuelve a contemplar con los privilegios y alternativas del espectador enterado. El texto, de esa manera, suele transformarse en una suerte de espectáculo o de estampa gráfica de sucesos muy variados. El cuadro de costumbres, como su indecisa nomenclatura lo indica, será, ante todo, una narración detallista que aspira a una perspectiva espacial en que se exaltan los rasgos y peculiaridades que nos sirven para caracterizar la escena en cuestión. De ahí la predilección por el detalle pintoresco, el sesgo regionalista y la manolería que pesa sobre la narración. Pero entiéndase que esa predilección por lo gráfico no produce la organización espacial de la materia narrativa - por cierto mucho más complejaque se insinúa en los primeros cuentos de Rubén Dario o en las Sonatas de Valle Inclán. El costumbrismo se empeñó, más bien, en una ornamentación efectista de escenas típicas; sólo que -como el lector podrá intuir - la literatura no puede apoyarse, como la pintura, 
en una concepción decorativa de la anécdota, ya que la percepción cromática y gráfica en el texto se dan mediante un proceso de analogías y paralelismos que son reflejos o sustitutos de la percepción directa y que sitúan la evocación en lugar de la experiencia óptica como tal.

Ese empeño por lograr una escritura dibujada aproxima el cuadro de costumbres - sobre todo en las Escenas de Estébanez- a la pintura de género propiamente dicha. En ese sentido, es curioso, por cierto, que los costumbristas una y otra vez, invitan a la contemplación del tex to como si se tratara de una creación plástica. Mesoneros, entre otros, lo subrayó más de una vez: "Propúseme desarrollar mi plan por medio de ligeros bosquejos o cuadros de caballete en que, ayudado de una acción dramática y sencilla, caracteres verosímiles y variados, y diálogo animado y castizo, procurase reunir en lo posible el interés y las condiciones principales de la novela y el drama."25 El concepto de lo verosímil a que alude Mesoneros es en parte lo que sustrae el contenido imaginario de la narración y hace que el personaje en vez de transformarse en un acto sutil de exploración, se convierta en un tipo que ilustra las caracterïsticas de un ambiente y que al mismo tiempo padece una escasísima vida interior.

En contraste directo con el cuento literario, el cuadro de costumbres aparece como una estructura abierta que sólo ocasionalmente remite a su propia hechura. Siempre es posible, claro está, seleccionar narraciones de esa indole en que se logran hallazgos perdurables. Tal sería, entre muchos ejemplos a mano, el caso de "El collar de perlas" de Estébanez, "El castellano viejo" de Larra, "El chapin" de Milla, y muy especialmente "El matadero" de Echeverrïa. Pero nótese que si esos textos resaltan es, principalmente, por lo que tienen de excepcionales como creaciones imaginativas.

Con los rasgos que he resumido hasta aquí se extendió por América la narración costumbrista. Sabemos además que en algunos países, notablemente en Colombia, Perú y Costa Rica, esas estampas saturaron el ámbito literario de la época. Al comentar la producción desorbitada de esas narraciones, Baldomero Sanín Cano señalaba que en Colombia "Hubo una época tiranizada por el cuadro de costumbres. El literato hacía el estreno de su vida literaria con obras de esta clase." Y en la página siguiente añade: "La ola romántica trajo entre nosotros la boga del cuadro de costumbres. Se abusó del género porque su aparente facilidad convidaba a los escritores inexpertos." 26 
Así, desafortunadamente, gran parte de la narrativa americana invertía su impulso creador en descripciones que se ocupan casi siempre de asuntos efímeros y de nuestros hábitos provincianos. Pero al adentrarnos en el costumbrismo americano, es necesario subrayar - porque no se ha insistido en ello con la precisión requerida - que en América, esas narraciones detallistas de matiz irónico tienen antecedentes precisos que no siempre remiten a los modelos europeos del siglo XIX; relatos estructuralmente muy próximos al cuadro de costumbres surgieron en América como desprendimientos imaginativos de la crónica histórica y pseudohistórica. Narraciones de esa índole abundan, por ejemplo, en los Comentarios reales (1609-1616) del Inca Garcilaso de la Vega y aparecen aún con más frecuencia en $E l$ carnero (1636) de Juan Rodríguez Freyle y la Historia general del Perú de Fray Martî́n de Murúa. 27 Son cuentos de temas muy variados que -como lo señaló Antonio C. Altamar-con los siglos darán pie a numerosos cuadros de costumbres y a varias tradiciones de Ricardo Palma. ${ }^{28}$

Ese entronque histórico-literario, de tan amplia significación en las letras americanas, produjo formas seminales para la narrativa de ficción $\mathrm{y}$, en mi opinión, es el antecedente primordial de nuestra literatura costumbrista. Hecho, que si bien se ve, fue oblicuamente subrayado en las primeras frases de "El matadero": "A pesar de que la mía es historia - dice Echeverräa- no la empezaré por el arca de Noé y la genealogía de sus ascendientes como acostumbraban hacerlo los antiguos historiadores de América que deben ser nuestros prototipos." 29

En América - por razones culturales e históricas que no podría elucidar aquí- el cuadro de costumbres diversificó sus metas. Las circunstancias variadǐsimas y casi siempre precarias del mundo americano no podían reducirse fácilmente a los esquemas burgueses que ofrecïan los modelos europeos. El argentino Juan María Gutiérrez (1809-1878), entre otros, no tardó en reconocerlo: "Debemos fijarnos antes en nuestras necesidades y exigencias, en el estado de nuestra sociedad y su indole, y sobre todo en el destino que nos está reservado en este gran drama del universo, en que los pueblos son actores. Tratemos de darnos una educación análoga y en armonía con nuestros hombres y con nuestras cosas; y si hemos de tener una literatura hagamos que sea nacional." 30 Alberdi, por su cuenta, admitra, con razón, que si "Larra no basta a España, basta mucho menos a la América." 31 Y es claro que en el mundo americano, el cuadro de costumbres asume una voluntad de afirmación cultural y 
de responsabilidad crítica que le lleva más allá del simple roman des moeurs. Con frecuencia la escritura suelta de esas estampas incorpora una tensión dialéctica que le aproxima al ensayo y que anticipa la orientación intelectual de la narrativa criollista del siglo XX.

Al tomar ese rumbo, los vî́nculos formales entre el cuadro de costumbres y el cuento literario - que entonces apenas despuntabaserán tangenciales por necesidad. Y cuando ambas formas se entrecruzan, el resultado es, en el mejor de los casos, una fusión de procedimientos desiguales. Ese desequilibrio formal, que he comentado en una lectura reciente de "El matadero," 32 se manifiesta con igual claridad en "Tres desenlaces ilógicos" de José López Portillo y Rojas (1850-1923) y "En el prefacio de Franciso Vera" de Tomás Carrasquilla (1858-1940). Ajeno aún a las sutilezas que exige el cuento literario, el cuadro de costumbres engloba con igual facilidad la perífrasis del refrán, la nota marginal o las descripciones de algún detalle curioso; detalle que accidentalmente puede dar pie a la materia anecdótica del texto. De ese ardid tantas veces utilizado, se vale una y otra vez José Caicedo Rojas al comentar en su relato "El tiple" el origen y peculiaridades de ese instrumento. Su narración, como casi todas las de su época, se convierte en una retahila arbitraria de apuntes ocasionales, coplas y resabios majaderos de erudición literaria: "Mas para un simple artículo de periódico hemos tomado el asunto de muy atrás: ni más ni menos como si para cantar la guerra de Troya nos hubiéramos remontado al nacimiento de Elena, cosa que no habría gustado mucho al viejo Horacio."33

Debido a la aceptación que alcanzaron narraciones de esa naturaleza puede afirmarse que el cuento romántico apareció, tanto en España como en América, en la periferia de la actividad literaria. En sus estadios iniciales, el cuento surge dominado por el ensimismamiento lírico e indeciso en su forma. "La suegra del diablo" de Fernán Caballero (1796-1877) y "El pájaro verde" de Juan Valera (1824-1901) son dos ejemplos adecuados de ese titubeo formal a que me he referido. Pero son, en todo caso, narraciones en que surge la tensión espasmódica que habia culminado en los textos de Hoffman y Poe. Rasgos de esa tensión imaginativa aparecian también en "Peregrinación a la luz del dỉa" de Juan Bautista Alberdi en que, según declaraciones suyas, quiso alcanzar "el cuento fantástico aunque menos fantástico que los de Hoffman." 34 Pero como lo ha consignado oportunamente Juan Carlos Ghiano, esas narraciones de Alberdi, entre otros, estaban igualmente próximas tanto a las creaciones de Hoffman como a las Lettres Persanes de Montesquieu y Las 
cartas marruecas de Cadalso. En la cuentǐstica argentina por ejemplo, el "Horacio Kalibang o los autómatas" de Eduardo L. Holmberg (1852-1937) y "Fantasia" de Tomás Guido (1818-1890) aparecen como testimonios endebles del cuento literario. Pero fue Roberto J. Payró (1867-1928), entre los narradores argentinos, acaso el primero en dominar las fórmulas esquivas del cuento literario.

En México, José María Roa Bárcena (1827-1908) con su relato "Lanchitas" y Manuel Payno (1810-1894) en "Tardes nubladas" se aproximaron discretamente a los refinamientos formales que requería el cuento. En esos textos despuntan ya el lenguaje preciso y las condensaciones estilisticas que inauguraban los relatos de Alphonse Daudet, Chekhov y Guy de Maupassant.

En sus formas más logradas el cuento perseguía las economías sutiles del lenguaje poético; discurso que sólo de manera ocasional encontraremos en el cuadro de costumbres. Hacia 1870 el cuento aportaba a las letras americanas algunos de los ejemplos más logrados de nuestra prosa de ficción. Es indiscutible, además que el proceso de refinamiento formal de la narración breve fue accidentalmente favorecido por los modernistas que vieron el cuento como sïntesis ideal del discurso narrativo. "El fardo" (1887) de Rubén Darioo es, en todos los órdenes, una elaboración finísima en que se equilibran el lenguaje recrudecido de los naturalistas y la delicadeza poética de los parnasianos. En ese texto - tan distante ya de los avatares descriptivos del costumbrismo- aparecen, entre otras cosas, las disyuntivas inquietantes del azar y de lo enigmático. Sin que su materia sea ajena al contexto, "El fardo" se consolida como un espacio imaginario que contiene en sî todas sus posibilidades; es una creación autárquica que engloba la totalidad de las circunstancias elegidas por el narrador. El texto de Darío fluye a partir de una causalidad que emite la estructura narrativa como tal. En contraste con la estampa costumbrista, en "El fardo" el móvil de la narración no es accidental o externo, sino que aparece en función de las exigencias que impone el discurso narrativo. De ahí el impacto indeleble que suele producir el cuento literario. Con esos relatos de Darío y "La mañana de San Juan" (1883) de Manuel Gutiérrez Nájera, entre otros, el cuento hispanoamericano se alejaba para siempre de la pirueta sintáctica y del material de relleno que aprovechó la narración costumbrista.

En el cuento la información no valdrá como tal, sino que se desdobla para suscitar nuevos planos de asociación. Lo que pudo ser un detalle ocasional en la narración costumbrista, en el cuento, a menudo, será el resorte que inicia un desenvolvimiento vertiginoso e 
inesperado de sucesos; sucesos que al vincularse al flujo del relato producen ese efecto de estallido o de coágulo emotivo que percibimos en "El almohadón de plumas" de Horacio Quiroga, en "El disparo" de Pushkin 35 o en muchos textos de Kafka. Pero es cierto, además, que en las letras americanas, relatos muy anteriores habian profetizado esa concepción intensa del discurso narrativo. "Fiebre amarilla" (1868) de Justo Sierra, por ejemplo, inauguraba con éxito procedimientos que hoy reconoceriamos como rasgos inherentes al cuento literario. 36

$\mathrm{Si}$ a fines de siglo el relato costumbrista agota sus posibilidades es porque aún insistía en postular una relación insostenible entre los convencionalismos literarios y la realidad circunstante. 37 En gran medida el desgaste imaginativo de la narración costumbrista radica, pues, en que el texto asume como orden primigenio la realidad exterior, y en que el discurso se constituye como signo de la misma. Desprovistos de otras posibilidades, esas estampas descriptivas se aferraron asiduamente al dato pintoresco y a los ripios de la historia. Es más que nada por esas razones que la narración costumbrista aparece hoy como una escritura envejecida que evoca la imagen borrosa del daguerrotipo. Es la narración en que -como dijera sabiamente Mark Schorer- "We are no longer in a position to say what life means, therefore we must content ourselves with telling how it looks." 38

El cuadro de costumbres y el cuento literario son, por decirlo así, dos creaciones que apuntan hacia niveles muy desiguales de la experiencia literaria. Es por ello que me parece un equívoco, en términos históricos y formales, proponer un alineamiento directo entre ambas tipologías narrativas, ya que no se trata -en términos estructurales- de dos estadíos consecutivos en la evolución de un género. Pero creo que si de ordinario se mantiene esa perspectiva, es porque el artículo de costumbres conquistó un espacio y un hábito de lectura que hoy de una forma $u$ otra asociamos con el cuento.

Vanderbilt University

ENRIQUE PUPO-WALKER

\section{NOTAS}

1. Véanse, por ejemplo, las observaciones que en ese sentido ofrece Antonio C. Altamar en su obra Evolución de la novela colombiana (Bogotá: Publicaciones del Instituto Caro y Cuervo, 1957), pp.i125-145. Agradezco al Research Council of Vanderbilt University el apoyo "que me brindó en la 
preparación de este estudio. Una versión reducida de este trabajo fue leída en la sesión de literatura hispanoamericana de la Modem Language Association, el 28 de diciembre, 1975.

2. Al referirme al "cuento literario" aludo al esquema narrativo que desarrolló el romanticismo y que fue inaugurado y definido por Edgar Allan Poe, entre otros, en su conocida reseña de Twice-Told Tales de N. Hawthorne. Ver The Complete Works of E. A. Poe (New York: Thomas Y. Crowell, 1902), pp. 106-113. Es obvio, por otra parte, que los costumbristas no distinguen el cuento como una forma definida y artísticamente superior al artǐculo de costumbres. Refiriéndose a ello José F. Montesinos señaló que "Mesoneros era hombre demasiado de su época para que la palabra cuento sea frecuente en su vocabulario; no hablemos de novela corta, término vergonzante, enteramente moderno. De pasada da a entender que el cuento ha sido siempre una sencilla narración en prosa y que es ridículo que los románticos lo escriban en verso; da a entender que, en estos tiempos, tales cuentos son cosas hechas para llenar las columnas de los periódicos -y aun en ese pasaje se habla de 'narraciones, episodios y cuentos,' vocablos que supongo da como sinónimos, y que en todo caso sería difícil deslindar y definir." Montesinos cita en una nota observaciones en que Mesoneros caracteriza al cuento como forma narrativa: "Ora se emplea en trazar la historia que puede pasar por novela, ora ... en escribir novelas que pican en historia; los unos se encargan del surtido al por mayor de narraciones, episodios, cuentos y traducciones para los periódicos." Costumbrismo y novela: ensayo sobre el redescubrimiento de la realidad española (Madrid: Editorial Castalia, 1960), pp. 60-61. Para un análisis preciso que contrasta la estructura del relato y la del artículo periodístico puede consultarse el estudio de Roland Barthes " $\mathrm{La}$ estructura del suceso," en Ensayos críticos (Barcelona: Seix-Barral, 1965), pp. 225-236.

3. En lo que se refiere a distinciones formales, hasta hoy los estudios más útiles son los de Mariano Baquero Goyanes, El cuento español en el siglo XX (Madrid: Consejo Superior de Investigaciones, 1949), pp. 62-92; Luis Leal, Historia del cuento hispanoamericano (México: Ediciones de Andrea, 1966), pp. 5-20; Pedro Lastra, El cuento hispanoamericano del siglo XIX (Santiago de Chile: Editorial Universitaria, 1972); Enrique Anderson Imbert, El cuento español (Buenos Aires: Editorial Columba, 1959), pp. 8-17. Un modelo en lo que se refiere al análisis estructural propiamente dicho se ofrece en el estudio de Roland Barthes "Introduction à l'analyse structurale des récits," Communications, VIII (1966), pp. 237-272.

4. , Las variantes estructurales del cuadro de costumbres fueron delineadas por Clifford M. Montgomery en Early Costumbrista Writers in Spain 1750-1830 (Philadelphia: University of Pennsylvania Press, 1931) y sobre todo por F. Courtney Tarr en "Romanticism in Spain and Spanish Romanticism," Bulletin of Spanish Studies, XVI (1939), pp. 26-37.

5. Prólogo, Obras de José María de Pereda (Madrid: Editorial Tello, 1884) I, p. 37. 
6. El estudio más completo en torno al cuadro de costumbres, como género, se debe a Frank M. Duffey, The Early Cuadro de Costumbres in Colombia (Chapel Hill: North Carolina Studies in The Romance Languages and Literature, 1956). A lo largo de este trabajo indico algunas fechas de textos y autores poco conocidos simplemente para documentar el proceso evolutivo de las tipologías narrativas que considero.

7. Prólogo, Apuntes de ranchería y otros escritos escogidos (Bogotá: Biblioteca Popular Colombiana, 1945), p. 7. La perspectiva histórica que postuló el romanticismo - vista sobre todo desde la literatura - ha sido analizada con admirable precisión por Harry B. Henderson III. Ver: "The Romantic Historians: The Structure of Historical Imagination" en Versions of The Past (New York: Oxford University Press, 1974), pp. 16-49.

8. Obras completas (Madrid: Renacimiento) I, p. 12.

9. Ver: Montesinos, pp. 53-74.

10. El intercambio indeciso de modelos y la incertidumbre que envuelve al cuadro de costumbres como género literario han sido comentados por E. Correa Calderón en su conocida obra Costumbristas españoles (Madrid: Aguilar, 1950) I, p. 634.

11. Obras completas (Buenos Aires: Carlos Casavalle, 1873) II, p. 17. El carácter indeciso de la teoría literaria en el siglo XIX -sobre todo en Hispanoamérića - se analiza en el estudio de Peter Earle, "Hacia una teorìa de los géneros: Hispanoamérica siglo XIX," Insula, no. 352 (1976), pp. 1 y 10.

12. Pienso que la función del marco escénico en las Novelas ejemplares es de otra indole. Esa dimensión particularizada o informativa de los textos cervantinos ha sido analizada recientemente por Ruth S. El Saffar en Novel to Romance: A Study of Cervantes' Novelas Ejemplares (Baltimore: The Johns Hopkins University Press, 1974), pp. 30-150.

13. Larra es, sin duda, el único narrador de la época que mantiene una actitud vigilante y crítica ante el contexto social y, más importante aun, ante su propia escritura. Refiriéndose a ello Montesinos apunta: "Larra que tenia el Quijote en la uña, supo siempre disimular hurtos, y la impresión que deja la rica prosa de sus artículos no es ciertamente la de un pastiche cervantesco," Costumbrismo y novela, p. 66.

14. De la picaresca, el cuadro de costumbres retuvo en sus formas más elementales, la proyección autobiográfica y los resabios característicos de las obras tardias: el detalle gráfico y el latiguillo burlón que suelen derivar en moraleja cursi. Véanse por ejemplo "La bolsa" (1837) y "La patrona de huéspedes" (1834) de Mesoneros Romanos en Escenas matritenses, Obras, p. 16.

15. Esa difusión llegó a producir, inclusive, manuales para relatar cuentos que vienen a ser una suerte de retórica primitiva del género. Al referirse a dichos manuales Peter Dunn observa: "But along with the telling of anecdotes, exchanges of repartee, practical jokes, acid comment and disparates, such as those to be found in the Diálogos de apacible entretenimiento, by Gaspar Lucas Hidalgo, there had been an increasing cultivation of the cuento, and in the 
narrator a growing consciousness of the craft." Castillo Solorzano and the Decline of the Spanish Novel (Oxford: Basil Blackwell, 1952), p. 4. Se refiere el profesor Dunn a obras tales como El galateo español (1582) de Lucas Gracián Dantisco y Conto na aldea (1619) de E. Rodrĭguez Lobo. El diálogo X de esta obra se titula por cierto: "De maneyra de contar historias en conversaçâo."

16. Las historias peregrinas es uno de los precedentes de mayor interés, ya que el narrador no sólo documenta la historia de pueblos y ciudades, sino que describe los personajes típicos y más notables de cada sitio; todo lo cual forma parte de lo que el autor relata como "De las excelencias de España." En mi opinión, su proximidad a los modelos italianos no desvirtúa la significación de este texto como registro de detalles típicos y de caracterǐsticas regionales.

17. Ver: La vie de Lazarillo de Tormes (Paris: Aubier, 1958), p. 37 y Lazarillo de Tormes y la picaresca (Madrid: Ariel, 1972), p. 50.

18. Entre muchos textos que anticipan el propósito documental de la narración costumbrista, puede señalarse la proposición que hace el autor del Viaje de Turquia al dirigirse a Felipe II diciéndole: "He querido pintar al bibo en este comentario a manera de diálogo a V. M. el poder, vida, origen y costumbres de su enemigo." Citado por Lázaro Carreter, Ibid., p. 56.

19. Ver: Cuentecillos tradicionales en la España del Siglo de Oro (Bordeaux: Institut D'Etudes Iberiques, 1971). Una versión más amplia de este valioso estudio será publicada por la Editorial Gredos.

20. Para más datos véase: Joseph E. Gillet, "Doña Bisodia y Santo Ficeto," Hispanic Review, X (1942), pp. 68-70 y Marìa Rosa Lida de Malkiel, "De Centurio al mariscal de Turena: fortuna de una frase de La Celestina," Hispanic Review, XXVII (1959), pp. 150-166.

21. Ver: Montesinos, pp. 41-53 y W. S. Hendrix, "Notes on Jouy's influence on Larra," Romanic Review, XI (1920), p. 37.

22. Ibid., p. 61.

23. El canasto del sastre (Guatemala: Tipografía Nacional, 1935), p. 32.

24. $Y$ es asĩ porqué el foco del artǐculo está casi siempre en lo sorpresivo del asunto y no en la singularidad del hecho. Ricardo Latcham al examinar las imperfecciones de la narrativa costumbrista apunta, con razón, que “Desde varios ángulos los románticos todavía se estrellaban con invencibles dificultades. Desconocian la técnica del relato, improvisaban, y constantemente sus esfuerzos servian mejor las finalidades políticas que la veracidad y pulcritud indispensables al creador." Antología del cuento hispanoamericano contemporáneo (Santiago de Chile: Zig-Zag, 1958), p. 13.

25. Panorama, p. 12.

26. Letras colombianas (México: Imp. Mundial, 1944), p. 94. En ese contexto interesa además la definición que ofrece José Manuel Marroquiñ del cuadro de costumbres, ya que alude tanto a los propósitos como a la estructura misma de la narración: "Un artǐculo de costumbres -dice Marroquîn- es la narración de uno o más sucesos, de los comunes y ordinarios, hecha en tono ligero y salpicada de observaciones picantes y de chistes de todo género. De esta 
narración ha de resultar o una pintura viva y animada de la costumbre de que se trata, o juntamente con esta pintura, la demostración de lo malo o de lo ridículo que haya en ella; más esta demostración han de hacerla los hechos por sĭ solos, sin que el autor tenga que introducir reflexiones o disertaciones morales para advertir al lector cuál es la conclusión que debe sacar de lo que ha leído." Citado por Altamar, p. 128.

27. Ver: José J. Arrom, "Precursores del cuento hispanoamericano: Fray Martìn de Murúa y el idilio indianista en $E l$ cuento hispanoamericano ante la crítica (Madrid: Editorial Castalia, 1973), pp. 24-36.

28. Ese proceso de fecundación se verifica en el estudio de Luis Loayza, "Dos versiones de una venganza," Creación y Crítica, 2 (1971), pp. 7-9. Mucho más agudo es el estudio de José J. Arrom, "Hombre y mundo en los cuentos del Inca Garcilaso" en Certidumbre de América (Madrid: Edit. Gredos, 1971), pp. 26-35. De interés es también el estudio de Eduardo Camacho Guizado en Estudios sobre literatura colombiana: siglos XVI y XVII (Bogotá: Universidad de los Andes, 1965), pp. 39-56.

29. Obras, V, p. 210.

30. Salón literario (Buenos Aires: Hachette, 1958), pp. 24-25.

31. Citado por J. C. Ghiano en El matadero de Echeverría y el costumbrismo (Buenos Aires: Centro Editor de América Latina, 1968), p. 68.

32. Ver: "Originalidad y composición de un texto romántico: El matadero de Esteban Echeverrïa" en El cuento hispanoamericano ante la crítica (Madrid: Castalia, 1973), pp. 37-49.

33. Cuadros de costumbres (Bogotá: Edit. Minerva S. F.), pp. 129-40.

34. (Buenos Aires: Edit. Choele-Choel, 1947), p. 11.

35. Es esa cualidad sutil y enormemente efectiva a la que se refiere Julio Cortázar en su conocido ensayo "Del cuento breve y sus alrededores:" "la tensión del cuento - dice Cortázar- nació de esa eliminación fulgurante de ideas intermedias, de etapas preparatorias, de toda retórica literaria deliberada, puesto que había en juego una operación en alguna medida fatal que no toleraba pérdida de tiempo." El último round (Buenos Aires, 1969), p. 38.

36. Esa narración ha sido minuciosamente estudiada por José J. Arrom en "Mitos taînos en las letras de Cuba, Santo Domingo y México." Cuademos Americanos, CLXVIII (1970), pp. 110-123.

37. Sobre esa engañosa equivalencia entre el texto y el ámbito descrito, consúltese el ensayo de F. Lázaro Carreter, "El realismo como concepto crítico literario," Cuademos Hispanoamericanos, Nos. 238-40 (1969), pp. 128-51. Esas contradicciones se comentan con una perspectiva mucho más amplia en Documents of Modern Literary Realism, Ed., George J. Becker. (Princeton: University Press, 1968).

38. "The necessity of Myth" en William Blake (New York: Henry Holt, 1946), p. 357. 
